\title{
Articulation Test Performances of Low-Income, African-American Preschoolers With Communication Impairments
}

\author{
Julie A. Washington \\ Holly K. Craig \\ University of Michigan, Ann Arbor, MI
}

\begin{abstract}
Culturally valid speech and language testing measures for use with African-American children who are speakers of Black English (BE) are limited. An alternative to developing new tests for use with this population is to adapt currently available tests designed for use with standard English speakers. The purpose of this study was to compare the responses of 28 low-income, urban African-American preschoolers from Metropolitan Detroit who were speakers of $\mathrm{BE}$ on the Arizona Articulation Proficiency Scale, using a standard English and a BE scoring procedure. The findings indicated that this test does not require a $\mathrm{BE}$ scoring adjustment for northern children who are speakers of BE.
\end{abstract}

KEY WORDS: articulation, assessment, Black English, preschoolers

Culturally fair speech and language assessment methods are limited for African-American children, despite the importance of culturally valid measures as the basis for educational and clinical decision making. The paucity of test instruments is felt keenly by speech-language pathologists working in the country's large cities, where the need to distinguish linguistic differences from delays and disorders is critical in populations of low-income, urban, African-American children who are speakers of Black English (BE). These children are seriously at risk for educational problems (Entwisle, 1968; Foreit \& Donaldson, 1971; Heath, 1986; Saville-Troike, 1986).

An efficient alternative to the development and standardization of completely new tests appropriate to this population would be to adapt and change tests that currently are available and widely used with children who are speakers of standard English (SE) (VaughnCooke, 1986). In two investigations comparing the articulation test performance of $\mathrm{BE}$ - and SE-speaking children, Seymour and Seymour (1981) and Haynes and Moran (1989) advocated the use of a bidialectal model or generation of local norms when interpreting the test performance of children who speak BE. Similarly, Taylor and Payne (1983) proposed that adjusted scores could be developed for many speech and language tests to provide a culturally valid assessment alternative.

Cole and Taylor (1990) modified three well-known articulation tests: the Templin-Darley Tests of Articulation, Second Edition (Templin \& Darley, 1969), the Arizona Articulation Proficiency Scale: Revised (AAPS-R) (Fudala, 1974), and the Photo Articulation Test (PAT) (Pendergast, Dickey, Stalley, Selman, \& Sorder, 1969). Two scores were assigned to each child's response: (a) a score based on the criteria published in the test manuals and consistent with standard English, and (b) a score based on the phonological rules of $\mathrm{BE}$. In addition to the potential improvement in the validity of these tests for assessing African-American children, interrater agreements for these adjusted scores were excellent, indicating that this method was also potentially reliable.

Cole and Taylor administered these tests to 10 AfricanAmerican first graders who attended a Mississippi public school. The children were from low-income homes, had clinically unremarkable histories, and were functioning at grade level according to teacher reports. Using the standard English scoring criteria, seven children were identified as articulation-impaired on the AAPS-R, six on the Templin-Darley, and three on the PAT. In contrast, the $B E$ scoring adjustment reduced these frequencies considerably: no children were identified as articulationimpaired on the AAPS-R, only two on the TemplinDarley, and one on the PAT. The Cole and Taylor findings indicate that the standard English scoring criteria for these tests do not correlate well with classroom functioning and may substantially increase the likelihood of faulty diagnostic judgments for low-income, AfricanAmerican children who are speakers of BE. The purpose of the current study was to apply the Cole and Taylor scoring adjustment on the AAPS-R to a clinical population. The Arizona Articulation Proficiency Scale was selected for administration because it is widely used, 
because it is appropriate for this young age, and because it showed the greatest shift in clinical interpretations within the previous research by Cole and Taylor (1990).

\section{METHOD}

\section{Subjects}

The subjects were 28 African-American boys $(n=19)$ and girls $(n=9)$ ages $4: 6$ to $5: 3$. The subjects were all preschoolers enrolled in a Metropolitan Detroit area public school program designed for at-risk children. Preschoolers enrolled in an at-risk public school program were selected for study because they were at a critical point in decision making for subsequent classroom placement and thus represented a clear example of the potential educational and clinical importance of this kind of adjustment. In addition, low-income, urban, AfricanAmerican children who are preschoolers would be relatively free from exposure to standard English, the typical mode of classroom instruction. The children's at-risk status was determined based on several criteria established by the school system, including low family income. The family's income status was ascertained utilizing a school-generated parent questionnaire and verified by obtaining copies of documents provided by the State Department of Social Services.

The preschool population from which this sample was drawn consisted of 3964 - and 5-year-old children, 250 of whom were African-American. Following an inservice provided by the experimenters, each classroom teacher was given a questionnaire and asked to answer a series of questions related to the communication abilities of the African-American children in their classrooms and then refer those children they considered to be poor communicators for speech and language assessments. All of the children who participated as subjects in this investigation were referred by the classroom teachers. None of the children had a prior history of speech or language intervention services.

Two groups of children with communication impairments were identified by the teacher's reports: impaired speech and nonimpaired speech. The impaired speech group ( $n=8$ ) was described by the teachers as having poor articulation skills. The nonimpaired speech group ( $n$ $=20$ ) was described as having good speech production skills, but as being poor communicators in the classroom, exhibiting deficiencies in vocabulary and sentence production skills. For the purposes of this investigation, these children were assigned to two groups, designated as impaired speech and nonimpaired speech, respectively. Each child passed a hearing screening bilaterally at $25 \mathrm{~dB}$ for $500,1,000,2,000$ and $4,000 \mathrm{~Hz}$ (American National Standards Institute, 1969).

\section{Data Collection}

The AAPS, 2nd edition (Fudala \& Reynolds, 1986) was administered to each child individually as part of a larger language-testing protocol. In addition, when pilot testing the current methods, the AAPS consistently elicited a response to every pictured vocabulary item by low-income, urban, African-American children who were speakers of BE. Although the second edition was the version of the AAPS administered, the earlier revised edition ( $\mathrm{Fu}-$ dala, 1974) consists of the same pictures and employs the same administration methods. The AAPS was administered and scored according to standard administration and scoring guidelines in a room free from distractions. The test was administered by a certified speech-language pathologist who was an African-American female and a native speaker of both $\mathrm{SE}$ and $\mathrm{BE}$.

\section{Data Scoring}

Subject responses first were scored using the scoring system published in the manual and designated as SE scoring, and a total score was derived. A second score, a $\mathrm{BE}$-adjusted score, was derived for each subject by allowing credit for any of the 12 test items identified by Cole and Taylor (1990) as those for which BE could be appropriately employed by the subjects (item numbers 10, 14, 17, 20, 22, $25,28,33,38,46,47,48$ ). The appendix presents each test item, the response defined as appropriate in the manual, and the BE alternative proposed by Cole and Taylor. The severity of articulation deviation was scored for both the $\mathrm{SE}$ and $\mathrm{BE}$ scoring procedures, and resulting shifts in interpretation of severity level were noted.

In addition to scoring each subject's responses on the second edition of the AAPS (1986), responses also were scored using the earlier revised edition of the AAPS (1974). This is the version of the AAPS utilized by Cole and Taylor (1990). No differences in administration and computation of the total scores exist across the earlier and later versions of the AAPS. The major difference between the two versions of this test relates to the interpretations of severity of articulation deviancy assigned by each. In the earlier test, three interpretations of a child's performance were possible: normal, moderate, and severe. In the second edition of the test, the interpretations were expanded to include mild articulation disorders. As a result of these changes, a different interpretation of severity level was possible for a given score, based on the version of the test used. An established SE total score, an adjusted BE total score, and an interpretation of articulatory severity were derived for each version of the AAPS. Shifts in interpretation based on the SE scoring system and the BE scoring system were recorded for each version.

\section{Reliability}

Interjudge reliability was established by audiotaping the responses of $10 \%$ of the subjects in this investigation. The data for two children in the nonimpaired speech group and one child in the impaired speech group who was highly unintelligible were examined. Their responses were retranscribed and rescored by an independent observer who 
was a certified speech-language pathologist. Interrater agreements on a point-to-point comparison for responses were high, $96 \%$ for transcription, $96 \%$ for BE adjusted scores, and $100 \%$ for interpreting severity levels.

\section{RES U L T S}

The AAPS total scores and adjusted total scores are presented in Table 1. The mean total score for the impaired speech group was significantly lower than the mean total score for the nonimpaired speech group $[t(26)=8.30$, $p<.01]$. The group differences confirmed the teachers' reports. The mean adjusted scores were also significantly different for the two groups $[t(26)=8.66, p<.01]$.

The adjusted mean total score was 81.1 for the impaired speech group and 95.4 for the nonimpaired speech group. The system of crediting the children's responses to the 12 targeted test items resulted in statistically significant gains for the impaired speech group [pairwise $t(7)=5.77$, $p<.01$ ] and for the nonimpaired speech group [pairwise $t(19)=4.36, p<.01]$. However, these adjusted gain scores failed to result in shifts in interpretation for 25 of 28 children on the revised version and for 26 of 28 children on the second edition of the test.
An item analysis was performed on each child's responses to the 12 test items targeted by Cole and Taylor. Table 2 displays the responses receiving credit using the Cole and Taylor adjustment. Consistent with the findings discussed above, both groups of children produced many responses that received scoring credit on the test without the need for the Cole and Taylor adjustment. Interestingly, however, most (90\%) of the nonimpaired speech group did receive an adjusted score for item \#38 (/// $\theta$ substitution for "mouth"), indicating that the same substitution pattern by the children in the impaired speech group probably is due to factors other than articulation proficiency, as proposed by Cole and Taylor. Test item number \#20 (/r/ in "car") was the only other one that received an adjusted score for a substantial number of children. All of these children were in the impaired speech group, however, and none of the children in the nonimpaired speech group required the adjustment in order to receive credit on that item.

\section{DIS C US S I ON}

The results of this study indicate that interpreting performances on the AAPS of preschool African-Ameri-

TABLE 1. Total scores (TS), adjusted total scores (ATS), and the interpretations of articulatory severity deviations (Interp) on the AAPS.

\begin{tabular}{|c|c|c|c|c|c|c|c|c|c|}
\hline \multirow[b]{2}{*}{ Subjects } & \multirow[b]{2}{*}{ Age } & \multirow[b]{2}{*}{$T S$} & \multirow[b]{2}{*}{ ATS } & \multicolumn{3}{|c|}{ Arizona-Revised } & \multicolumn{3}{|c|}{ Arizona-Second Edition } \\
\hline & & & & $\begin{array}{l}\text { Interp } \\
\quad T S\end{array}$ & $\begin{array}{l}\text { Interp } \\
\text { ATS }\end{array}$ & Shift & $\begin{array}{l}\text { Interp } \\
\quad T S\end{array}$ & $\begin{array}{l}\text { Interp } \\
\text { ATS }\end{array}$ & Shift \\
\hline \multicolumn{10}{|l|}{ Impaired speech } \\
\hline 1 & $5: 0$ & 68.0 & 72.0 & $\mathbf{S}$ & $\mathbf{S}$ & - & $\mathbf{S}$ & $\mathbf{S}$ & - \\
\hline 2 & $5: 0$ & 71.5 & 74.0 & $\mathbf{S}$ & $\mathbf{S}$ & - & $\mathrm{S}$ & $\mathbf{S}$ & - \\
\hline 3 & $5: 0$ & 81.0 & 84.0 & $\mathbf{S}$ & Mod. & + & Mild & Mild & - \\
\hline 4 & $5: 0$ & 81.0 & 82.0 & $\mathbf{S}$ & Mod. & + & Mild & Mild & - \\
\hline 5 & $4: 11$ & 81.0 & 84.0 & $S$ & Mod. & + & Mild & Mild & - \\
\hline 6 & $4: 7$ & 81.5 & 83.0 & Mod & Mod. & - & Mild & Mild & - \\
\hline 7 & $5: 1$ & 84.0 & 85.0 & Mod. & Mod. & - & Mild & $\mathbf{N}$ & + \\
\hline 8 & $4: 9$ & 80.5 & 84.5 & Mod. & Mod. & - & Mild & $\mathbf{N}$ & + \\
\hline \multicolumn{10}{|c|}{$\begin{array}{l}\text { Mean } \\
\text { Nonimpaired speech }\end{array}$} \\
\hline 1 & $4: 10$ & 89.5 & 90.5 & $\mathbf{N}$ & $\mathbf{N}$ & - & $\mathbf{N}$ & $\mathbf{N}$ & - \\
\hline 2 & $5: 2$ & 99.5 & 100.0 & $\mathbf{N}$ & $\mathbf{N}$ & - & $\mathbf{N}$ & $\mathbf{N}$ & - \\
\hline 3 & $4: 10$ & 93.5 & 94.0 & $\mathbf{N}$ & $\mathbf{N}$ & - & $\mathbf{N}$ & $\mathbf{N}$ & - \\
\hline 4 & $4: 9$ & 95.5 & 96.0 & $\mathbf{N}$ & $\mathbf{N}$ & - & $\mathbf{N}$ & $\mathbf{N}$ & - \\
\hline 5 & $4: 10$ & 95.0 & 97.5 & $\mathbf{N}$ & $\mathbf{N}$ & - & $\mathbf{N}$ & $\mathbf{N}$ & - \\
\hline 6 & $5: 0$ & 92.0 & 92.5 & $\mathbf{N}$ & $\mathbf{N}$ & - & $\mathbf{N}$ & $\mathbf{N}$ & - \\
\hline 7 & $4: 9$ & 92.5 & 93.5 & $\mathbf{N}$ & $\mathbf{N}$ & - & $\mathbf{N}$ & $\mathbf{N}$ & - \\
\hline 8 & $4: 11$ & 95.5 & 95.5 & $\mathbf{N}$ & $\mathbf{N}$ & - & $\mathbf{N}$ & $\mathbf{N}$ & - \\
\hline 9 & $4: 7$ & 89.0 & 92.0 & $\mathbf{N}$ & $\mathbf{N}$ & - & $\mathbf{N}$ & $\mathbf{N}$ & - \\
\hline 10 & $4: 6$ & 96.0 & 96.5 & $\mathbf{N}$ & $\mathbf{N}$ & - & $\mathbf{N}$ & $\mathbf{N}$ & - \\
\hline 11 & $4: 7$ & 96.0 & 96.5 & $\mathbf{N}$ & $\mathbf{N}$ & - & $\mathbf{N}$ & $\mathbf{N}$ & - \\
\hline 12 & $4: 10$ & 96.0 & 96.5 & $\mathbf{N}$ & $\mathbf{N}$ & - & $\mathbf{N}$ & $\mathbf{N}$ & - \\
\hline 13 & $5: 3$ & 100.0 & 100.0 & $\mathbf{N}$ & $\mathbf{N}$ & - & $\mathbf{N}$ & $\mathbf{N}$ & - \\
\hline 14 & $4: 8$ & 90.0 & 93.5 & $\mathbf{N}$ & $\mathbf{N}$ & - & $\mathbf{N}$ & $\mathbf{N}$ & - \\
\hline 15 & $5: 0$ & 99.5 & 100.0 & $\mathbf{N}$ & $\mathbf{N}$ & - & $\mathbf{N}$ & $\mathbf{N}$ & - \\
\hline 16 & $4: 6$ & 89.0 & 89.5 & $\mathbf{N}$ & $\mathbf{N}$ & - & $\mathbf{N}$ & $\mathbf{N}$ & - \\
\hline 17 & $4: 8$ & 96.0 & 97.0 & $\mathbf{N}$ & $\mathbf{N}$ & - & $\mathbf{N}$ & $\mathbf{N}$ & - \\
\hline 18 & $4: 7$ & 98.5 & 99.0 & $\mathbf{N}$ & $\mathbf{N}$ & - & $\mathbf{N}$ & $\mathbf{N}$ & - \\
\hline 19 & $5: 0$ & 97.0 & 98.0 & $\mathbf{N}$ & $\mathbf{N}$ & - & $\mathbf{N}$ & $\mathbf{N}$ & - \\
\hline 20 & $4: 11$ & 85.5 & 89.0 & $\mathbf{N}$ & $\mathbf{N}$ & - & $\mathbf{N}$ & $\mathbf{N}$ & - \\
\hline Mean & & $\overline{94.3}$ & 95.4 & & & & & & \\
\hline
\end{tabular}

Note: $\mathrm{S}=$ severe; $\mathrm{N}=$ normal; mod. = moderate. 
TABLE 2. The percentage of children in each group credited with adjusted scores (X) for each of the test items.

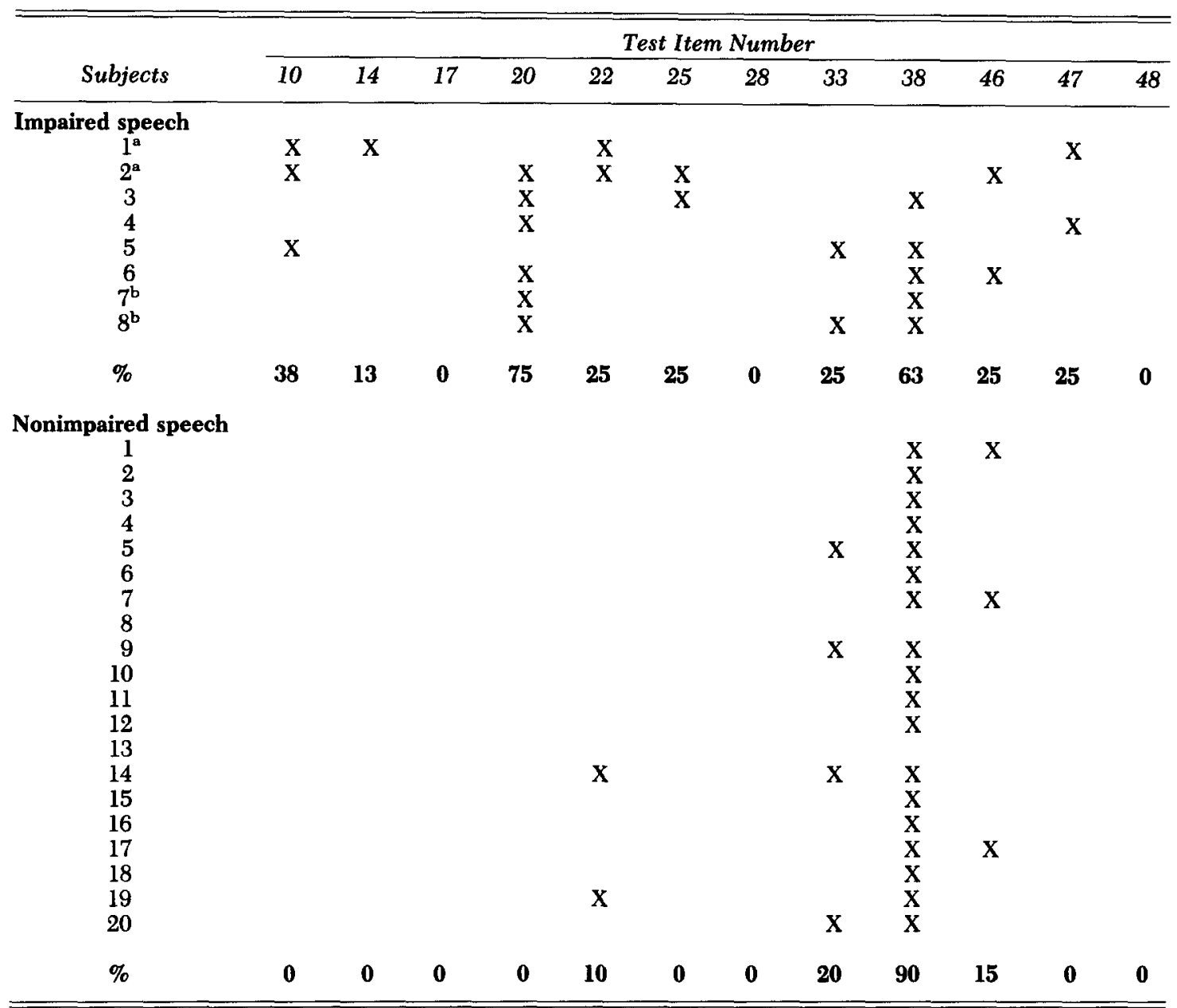

a Severe speech disorder

${ }^{b}$ Credit for BE changed status from mild to normal

can children who are considered to be poor communicators by their teachers is not altered appreciably by adjusting their scores for BE features. The scoring systems published in the manuals for both the AAPS-Revised and the AAPS-Second Edition do not seem to penalize the BE-speaking preschooler to a degree that is clinically significant. These data indicate that the AAPS will be a useful clinical assessment tool with this population. It is noteworthy, however, that the revised version and the second edition differ substantially from each other. The second edition yields finer clinical distinctions in terms of severity of the articulation impairment.

The current findings stand in sharp contrast to those reported for the AAPS in previous work by Cole and Taylor (1990). Their earlier study examined children considered to be functioning at grade level by their teachers. It is interesting that the current findings even for the group of children with nonimpaired speech failed to replicate those of Cole and Taylor. Most responses by most children in the present study received credit using the scoring systems published in the manuals. The BE adjustment was unnecessary. The differences between studies, therefore, are not attributable simply to the differences between subject groups (i.e., between apparently normal and reportedly poor communicators) because the direction of the differences is counterintuitive.

The children in these two studies resided in different geographical regions. The Cole and Taylor subjects were from Mississippi, whereas those in the present study were from Michigan. Fasold (1981) and Wolfram (1986) made a meticulous attempt to distinguish $\mathrm{BE}$ linguistic features from vernacular English spoken by low-income whites and from the many regional dialects that influence the two. Southern English, a regional dialect described by Fasold (1981) includes deletion of postvocalic /r/ (e.g., AAPS item \#20 "car," \#25 "ladder"), /g/-dropping (e.g., AAPS item \#22 "swinging"), and voiced alveolar stop pronunciation of "th" (e.g., AAPS item \#33 "that" or "this"). In contrast, Fasold reports that f/ $\theta$ substitutions (AAPS item \#38 "mouth" or "teeth") and final cluster reductions (AAPS items \#17 "bird," \#38 "cold," \#46 "nest," \#37 "carrots," \#48 "books") are observable in Southern English dialects but are more clearly a characteristic of BE. The only item on the AAPS that seems a 
candidate for a $\mathrm{BE}$ adjustment would be item \#38. This f/ $\theta$ substitution was observed consistently across both studies and, therefore, probably reflects $\mathrm{BE}$ regardless of regional dialect.

The failure of the present data to replicate those of Cole and Taylor seems best explained as reflecting differences in regional dialects. The Cole and Taylor adjustment may be better conceptualized as a change accommodating Southern English rather than BE. It would have been helpful to know how low-income, white 4- and 5-yearolds in Mississippi perform on the AAPS. This is not to imply, however, that their $\mathrm{BE}$ adjustment is either inappropriate or unwarranted. For children residing in that geographical locale, the adjustment should be made as Cole and Taylor proposed. The basis for recommending the adjustment, however, seems as clearly motivated by the Southern English dialect as BE. Indeed, Haynes and Moran (1989) and Seymour and Seymour (1981) have cautioned that their subject's speech characteristics were likely influenced by geographical regions. Future research may need to distinguish southern $B E$ and northern BE.

Most of the children in the impaired speech group in the present study received adjusted credit for item \#20 on the AAPS. This item targets postvocalic $/ \mathbf{r} /$ and was deleted by six of the eight subjects. Difficulty producing $/ \mathrm{r} /$ is a common pattern for children with articulation impairment (Ingram, 1981; Weiss, Lillywhite, \& Gordon, 1980). The omission of this phoneme seems more attributable to articulation proficiency status than $\mathrm{BE}$ dialect. This interpretation gains further support from the speech production profiles of the children with nonimpaired speech, who all produced the target $/ r /$ on that test item.

In conclusion, the results of this investigation revealed that the application of scoring adjustments to the AAPS total scores of 28 Midwestern, BE-speaking children produced no clinically significant differences. The scoring system proposed in the AAPS manual did not penalize these children for utilizing BE speech production features. These findings differed appreciably from those of Cole and Taylor (1990). They found that adjustment of scores on the AAPS to allow credit for BE articulation features resulted in significant changes for $60 \%$ of their subjects. The subjects in this investigation and those in the Cole and Taylor study differed primarily by geographic locale. The children were northerners and southerners, respectively. These findings suggest a need to consider regional dialects as well as cultural dialects when studying the speech characteristics of this population.

\section{REFERENCES}

American National Standards InStituTe (1969). Specifications for audiometers. (ANSI S3.6-1969). New York: Author.

Cole, P. A., \& TAYLOR, O. L. (1990). Performance of working class African-American children on three tests of articulation. Language, Speech, and Hearing Services in Schools, 21, 171-176.

ENTWISLE, D. R. (1968). Developmental sociolinguistics: Innercity children. The American Journal of Sociology, 74, 39-49.

FASOLD, R. W. (1981). The relation between black and white speech in the south. American Speech, 56, 163-189.

ForeIT, K. G., \& Donaldson, P. L. (1971). Dialect, race, and language proficiency: Another dead heat on the merry-goround. Child Development, 42, 1572-1574.

Fudala, J. B. (1974). Arizona Articulation Proficiency Scale: Revised. Los Angeles: Western Psychological Services.

FudALA, J. B., \& REYNOLDS, W. M. (1986). Arizona Articulation Proficiency Scale: Second Edition. Los Angeles: Western Psychological Services.

HAYNES, W. O., \& MORAN, M. J. (1989). A cross-sectional developmental study of final consonant production in southern black children from preschool through third grade. Language, Speech, and Hearing Services in Schools, 20(4), 400-406.

HEATH, S. B. (1986). Taking a cross-cultural look at narratives. Topics in Language Disorders, 7, 84-94.

INGRAM, D. (1981). Procedures for the phonological analysis of children's language. Baltimore: University Park Press.

Pendergast, K., Dickey, Stalley, E., Selman, J. W., \& SorDER, A. L. (1969). Photo Articulation Test. Illinois: Interstate.

SAVILLE-TROIKE, M. (1986). Anthropological considerations in the study of communication. In O. L. Taylor (Ed.), Nature of communication disorders in culturally and linguistically diverse populations (pp. 47-72). San Diego, CA: College Hill Press, Inc.

Seymour, H. N., \& SEYMOUR, C. M. (1981). Black English and Standard American English contrasts in consonantal development of four- and five-year-old children. Journal of Speech and Hearing Disorders, 46(3), 274-280.

TAYLOR, O. L., \& PAYNe, K. T. (1983). Culturally valid testing: A proactive approach. Topics in Language Disorders, 3, 8-20.

TEMPLIN, M. C., \& DARLEY, F. L. (1969). The Templin-Darley Tests of Articulation, (2nd ed.). Iowa City: Bureau of Educational Research and Service, Division of Extension and University Services, University of Iowa.

VAUGHN-COOKE, F. B. (1986). The challenge of assessing the language of nonmainstream speakers. In O. L. Taylor (Ed.), Treatment of communication disorders in culturally and linguistically diverse populations (pp. 23-48). Boston, MA: College-Hill Press, Inc.

WeIsS, C. E., Lillywhite, H. S., \& GoRdon, M. E. (1980). Clinical management of articulation disorders. St. Louis: C. V. Mosby Company.

WOLFRAM, W. (1986). Language Variation in the United States. In O. L. Taylor (Ed.), Nature of communication disorders in culturally and linguistically diverse populations (pp. 73-115). San Diego, CA: College-Hill Press, Inc.

Received February 11,1991
Accepted July 1,1991

Contact author: Julie A. Washington, PhD, Communicative Disorders Clinic, University of Michigan, 1111 E. Catherine Street, Ann Arbor, MI 48109-2054. 